\title{
Suppression of Samson Phase Formation in Al-Mg Alloys by Boron Addition
}

\author{
R. Goswami* and S. B. Qadri \\ Materials Science and Technology Division \\ Naval Research Laboratory, Washington DC 20375, USA
}

\begin{abstract}
Al-Mg alloys, particularly Al 5083 and Al 5456, are widely used for boat and ship structural applications because of their unique properties such as lightweight, high strength and good weldability. However, structural parts manufactured with these alloys fail catastrophically as a result of the formation of $\mathrm{Al}_{3} \mathrm{Mg}_{2}$, known as Samson phase, at grain boundaries. Here we demonstrate that the Samson phase formation is suppressed in $\mathrm{Al} 5083$ by alloying with B, which traps most of Mg in solid solution as $\mathrm{AlMgB}_{2}$ phase. This decreases the supersaturation level of $\mathrm{Mg}$ in $\mathrm{Al}$ matrix, which is a driving force for the formation of Samson phase in $\mathrm{Al}$ 5083. We observe Cu-rich precipitates, instead of the Samson phase, at grain boundaries upon extended annealing at $150^{\circ} \mathrm{C}$. This is a significant finding as it provides new insight as to how to minimize the longstanding problem of sensitization.
\end{abstract}

Key words: Al-Mg alloys, Sensitization, Samson Phase, Grain boundary precipitation, TEM

\section{Introduction}

Considerable work has been done on the complex $\mathrm{Al}_{3} \mathrm{Mg}_{2}$ intermetallic compound, known as Samson phase [1]. It is a cubic structure with space group: $\mathrm{m} 3 \mathrm{~m}$, lattice parameter $28.239 \AA$ and 1170 atoms per unit cell. In Al-Mg alloys, particularly in Al 5083 and $\mathrm{Al}$ 5456, this phase precipitates out from the supersaturated Al-Mg solid solution as a result of thermal exposure in the range of $50-200^{\circ} \mathrm{C}$ $[2,3,4,5]$. It mostly forms at grain boundaries in Al-Mg alloys, which makes them susceptible to intergranular corrosion (IGC) and stress corrosion cracking (SCC) as the grain boundary intermetallic phase is highly anodic relative to the $\mathrm{Al}$ matrix. This leads to a catastrophic structural failure via anodic dissolution of the grain boundary phase upon exposure to seawater and stress [3]. It is a longstanding problem of naval vessels, which use Al 5000 series alloys in order to decrease the overall weight and fuel consumption, and to increase the speed.

Recently, different thermo mechanical treatments [6], alloy additions of $\mathrm{Sr}, \mathrm{Nd}$ and $\mathrm{Zn}[5,7,8]$ and local reversion of thermal treatments [9] have been applied to minimize the formation of the grain boundary Samson phase and sensitization. However, these methods are not effective in preventing the formation of grain boundary $\mathrm{Al}_{3} \mathrm{Mg}_{2}$. We report here for the first time the prevention of this phase at grain boundaries in $\mathrm{Al} 5083$ by alloying with $\mathrm{B}$ and $\mathrm{Cu}$ that reduces the supersaturation of $\mathrm{Mg}$, which is the thermodynamic driving force for the precipitation of $\mathrm{Al}_{3} \mathrm{Mg}_{2}$ in $\mathrm{Al}$ matrix. Small additions of boron have been reported to enhance the creep-rupture resistance of superalloys [10]. Usually boron in superalloys segregates to grain boundaries because of its large size misfit with nickel and modifies the grain boundary chemistry.

\footnotetext{
${ }^{*}$ Corresponding author, e-mail: ramasis.goswami@nrl.navy.mil
} 


\section{Experimental}

An ingot with Al-5083 with some amount of $\mathrm{B}$ and $\mathrm{Cu}$ was produced by arc melting in an inert atmosphere. Such ingot was melted several times to ensure the homogeneity, and allowed to cool in the furnace. We have added $\approx 2.0 \mathrm{wt} . \% \mathrm{~B}$ and $\approx 0.75 \mathrm{wt} \% \mathrm{Cu}$ to Al 5083, which contains $\approx 94 \mathrm{wt} . \% \mathrm{Al}, \approx$ 4.5 wt. $\% \mathrm{Mg}$ and small amount of $\mathrm{Mn}, \mathrm{Fe}$ and $\mathrm{Cr}$. The ingot was homogenized at $500^{\circ} \mathrm{C}$ for $2 \mathrm{~h}$ and annealed at $150^{\circ} \mathrm{C}$ for $\approx 190 \mathrm{~h}$. Samples for TEM were prepared using an ion mill with a gun voltage of 4 $\mathrm{kV}$ for each gun, and a sputtering angle of $10^{\circ}$. A JEOL-2200FX analytical transmission electron microscope was then employed to examine the microstructure and composition. Fine-probe energy dispersive X-ray spectroscopy (EDS) was used to determine the distribution of $\mathrm{B}, \mathrm{Cu}$ and $\mathrm{Al}$. Further compositional information was obtained with high-angle annular dark field (HAADF) imaging. For structural analysis, we use x-ray diffraction (XRD) using Rigaku diffractometer utilizing $\mathrm{Cu} \mathrm{K} \alpha 1$ radiation.

\section{Results and Discussion}

Boron is known to form di-boride compounds, $\mathrm{MgB}_{2}$ and $\mathrm{AlB}_{2}$, with $\mathrm{Mg}$ and $\mathrm{Al}$, respectively. These di-boride compounds crystallize in hexagonal $(\mathrm{P} 6 / \mathrm{mmm})$ structure with lattice parameters, $\mathrm{a}=3.08 \AA$ and $\mathrm{c}=3.51 \AA$ for $\mathrm{MgB}_{2}, \mathrm{a}=3.01 \AA$ and $\mathrm{c}=3.24 \AA$ for $\mathrm{AlB}_{2}$. In the present work, however, the ternary Al-Mg boride particles, as evidenced by XRD and TEM, form in $\mathrm{Al}$ matrix. As the $\mathrm{MgB}_{2}$ and $\mathrm{AlB}_{2}$ have the same structure, one would expect solubility of $\mathrm{Mg}$ in $\mathrm{AlB}_{2}$ lattice, and it is more likely to substitute the $\mathrm{Al}$ atoms in the $\mathrm{AlB}_{2}$ lattice.

Fig. 1(a) shows the HAADF image of one such rod-like boride particle in an Al matrix in the ascast condition. The fine-probe EDS map shows that it is an Al-Mg ternary boride particle with considerable amount of $\mathrm{Mg}$. The distribution of $\mathrm{Al}, \mathrm{Mg}$ and $\mathrm{B}$ in the boride particle and matrix is shown in Fig.1 (b-e), respectively. A line scan, Fig. 1(f), across the particle shows considerable drop in Al counts close to the broad faces as compared to the core, suggesting that $\mathrm{AlB}_{2}$ forms initially during solidification and then $\mathrm{Mg}$ diffuses through the broad faces. In addition, Cu-rich precipitates, appeared bright in the HAADF image, were observed on top of the boride particle.

X-ray diffraction (XRD), Fig. 2, clearly shows $\alpha-\mathrm{Al}, \mathrm{Al}_{2} \mathrm{Cu}$ and $\mathrm{AlMgB}_{2}$ phases upon extended annealing at $150^{\circ} \mathrm{C}$ of this alloy. Note that the peaks corresponding to $2 \theta=27.187$ and 56.14 have been shifted to the lower angles as compared to the 0001 and 0002 of $\mathrm{AlB}_{2}$, suggesting that the c-parameter increases as a result of insertion of $\mathrm{Mg}$ in $\mathrm{AlB}_{2}$ lattice. In fact, the c-parameter of the boride phase is $3.28 \AA$, while the a-parameter does not change significantly with respect to $\mathrm{AlB}_{2}$. Using Vegard's law, the ratio of $\mathrm{Al}$ and $\mathrm{Mg}$ in the ternary boride turns out to be $\approx 3: 1$. Fig. 3 is a HRTEM image obtained from a portion of rod-like $\mathrm{AlMgB}_{2}$ particle showing the lattice fringes of 0001, 10-10 and 10-11 planes close to the [-12-10] zone. The corresponding fast Fourier transform (FFT) obtained from part of the image is given as a right inset, showing the 0001, 10-10 reflections with d-spacing $\approx 3.28 \AA$ and $\approx 2.6$ $\AA$, respectively, which is consistent with XRD observations.

In $\mathrm{Al} \mathrm{5083,} \mathrm{the} \mathrm{Mg}$ in solid solution strengthens the $\mathrm{Al}$ matrix through solid-solution hardening. The formation of $\mathrm{AlMgB}_{2}$ in $\mathrm{Al}$ matrix decreases the $\mathrm{Mg}$ level in solid solution and reduces the strength. The addition of $\mathrm{Cu}$, however, results in the formation of several $\mathrm{Cu}$-rich nanocrystalline precipitates. Figs. 4 (a-d) show nanocrystalline $\mathrm{Al}_{2} \mathrm{Cu}\left(\theta^{\prime}\right), \mathrm{Al}_{2} \mathrm{CuMg}$ (S-phase) [11] and $\Omega$-phase [12] precipitates in the matrix upon extended annealing. All these $\mathrm{Cu}$-rich precipitates enhance the strength of the alloy. 
To study the grain boundary microstructure, we examined number of grain boundaries for samples annealed at $150^{\circ} \mathrm{C}$ for $190 \mathrm{~h}$ in $\mathrm{HAADF}$ imaging mode. In this imaging mode, the brighter regions correspond to heavier atoms, as the scattering cross-section is proportional to $\mathrm{Z}^{2}$ (atomic number). Fig. 4 (e) is a typical HAADF image showing the grain boundary precipitates. Most precipitates appeared bright in the HAADF imaging mode, suggesting that these precipitates are $\mathrm{Cu}$ rich. These precipitates are mostly S-phase. In the HAADF imaging mode, however, the Samson phase, $\mathrm{Al}_{3} \mathrm{Mg}_{2}$, as it is enriched with $\mathrm{Mg}$, appears darker as compared to the matrix [2,3,4]. We present the microstructure of the Samson phase at a grain boundary without the addition of $\mathrm{B}$ and $\mathrm{Cu}$ (see Fig. 4(f-i)) taken in HAADF mode from a highly sensitized Al 5083 (sensitized at $175^{\circ} \mathrm{C}$ for $240 \mathrm{~h}$ ) for comparison. Specifically, TEM observations revealed that the $\mathrm{Mg}$ rich $\beta$ phase formed a continuous film at a number of grain boundaries after annealing the sample at $175^{\circ} \mathrm{C}$. An EDS line scan, (see Fig. 4(g), extracted from a region indicated by arrow in Fig. 4(f), and the fine probe EDS maps of $\mathrm{Mg}$ and $\mathrm{Al}$ across this boundary showed the enrichment of Mg (Figs. 4h and 4i), respectively.

\section{Summary and Conclusions}

We demonstrated that the Samson phase formation in Al 5083 has been suppressed by alloying with B and $\mathrm{Cu}$. TEM and XRD revealed that a ternary boride compound, $\mathrm{AlMgB}_{2}$, forms along with $\mathrm{Cu}$-rich nanocrystalline precipitates in $\mathrm{Al}$ matrix. The $\mathrm{AlMgB}_{2}$ phase formation decreases the supersaturation level of $\mathrm{Mg}$ in $\mathrm{Al}$ matrix, which is a driving force for the formation of Samson phase in Al 5083. Upon extended annealing at $150^{\circ} \mathrm{C}$, we observe $\mathrm{Cu}$-rich precipitates, instead of Samson Phase, at grain boundaries.

\section{Acknowledgment}

Funding for this project was provided by the Office of Naval Research (ONR) through the Naval Research Laboratory's 6.1 Research Program.

\section{References}

1. S. Samson, Acta Cryst., 19 (1965) 401-413

2. R. Goswami, G. Spanos, P.S. Pao and R. L. Holtz, Mat. Sci. Engg. A, 527 (2010) 1089

3. R. Goswami, P.S. Pao, G. Spanos and R.L. Holtz, Metal Trans, 42A (2011) 348

4. $\quad$ R. Goswami and R.L. Holtz, Metal Trans. A, 44 (2013) 1279

5. R. Zhang, S.P. Knight, R.L. Holtz, R. Goswami, C.H.J. Davies and N. Birbilis, Corrosion 2016, 72, 144-159

6. A. Halap, T. Radetic, M. Popovic, E. Romhanji, Metal. Mater. Trans. A, 45 (2014) 4572

7. Y. Wang, R.K. Gupta, N.L. Sukiman, R. Zhang, C.H.J. Davies and N. Birbilis, Coros. Sci. 73, (2013) 181

8. $\quad$ R.K. Gupta, R. Zhang, C.H.J. Davies and N. Birbilis, Corrosion 70 (2014) 402

9. L. Kramar, M. Phillippi, W.T. Tack, C. Wong, J. Mat. Eng. Performance, 21 (2012) 1025

10. Q.Z. Chen, N. Jones, D.M. Knowles, Acta Mater. 50 (2002) 1095

11. Y. Mou, J.M. Howe and E.A. Starke, Jr., Metal. Mater. Trans. A 26A (1995) 1591

12. S.P. Ringer, K. Hono, I.J. Polmear, T. Sakurai, Acta Mater., 44 (1996) 1883 


\section{Figure Captions}

Fig. 1 (a) A HAADF image showing the rod like boride particle. (b-e) Fine probe EDS maps showing the distribution of $\mathrm{B}, \mathrm{Mg}, \mathrm{Al}$ and $\mathrm{Cu}$, respectively. (f) A line-scan across the particle.

Fig. 2 XRD showing the $\mathrm{AlMgB}_{2}$ and $\mathrm{Al}_{2} \mathrm{Cu}$ precipitates in $\mathrm{Al}$ matrix. Inset shows the $10-11$ boride peak.

Fig. 3 HRTEM image of the boride particle. A low magnification image of the particle and the FFT pattern are shown as left and right insets, respectively.

Fig. 4. TEM images showing different precipitates in $\mathrm{Al}$ matrix. a) $\mathrm{Al}_{2} \mathrm{Cu}$ b) $\mathrm{A}$ multibeam image showing the $\mathrm{S}$ and $\mathrm{T}_{1}$ precipitates. (c and d) HRTEM images of $\mathrm{T}_{1}$ and $\mathrm{S}$-phase close to [11-2] zone of Al. The corresponding FFTs obtained from part of the matrix and precipitate are shown as insets. (e) A HAADF image showing $\mathrm{Cu}$-rich precipitates at grain boundary for sample annealed at $150^{\circ} \mathrm{C}$ for $190 \mathrm{~h}$. (f) A HAADF image of grain boundary $\beta$-phase in sensitized Al 5083. (g) The Line scan across the interface showing the distribution of $\mathrm{Al}$ and $\mathrm{Mg}$. (i) and (j) EDS maps of $\mathrm{Mg}$ and $\mathrm{Al}$, respectively. 


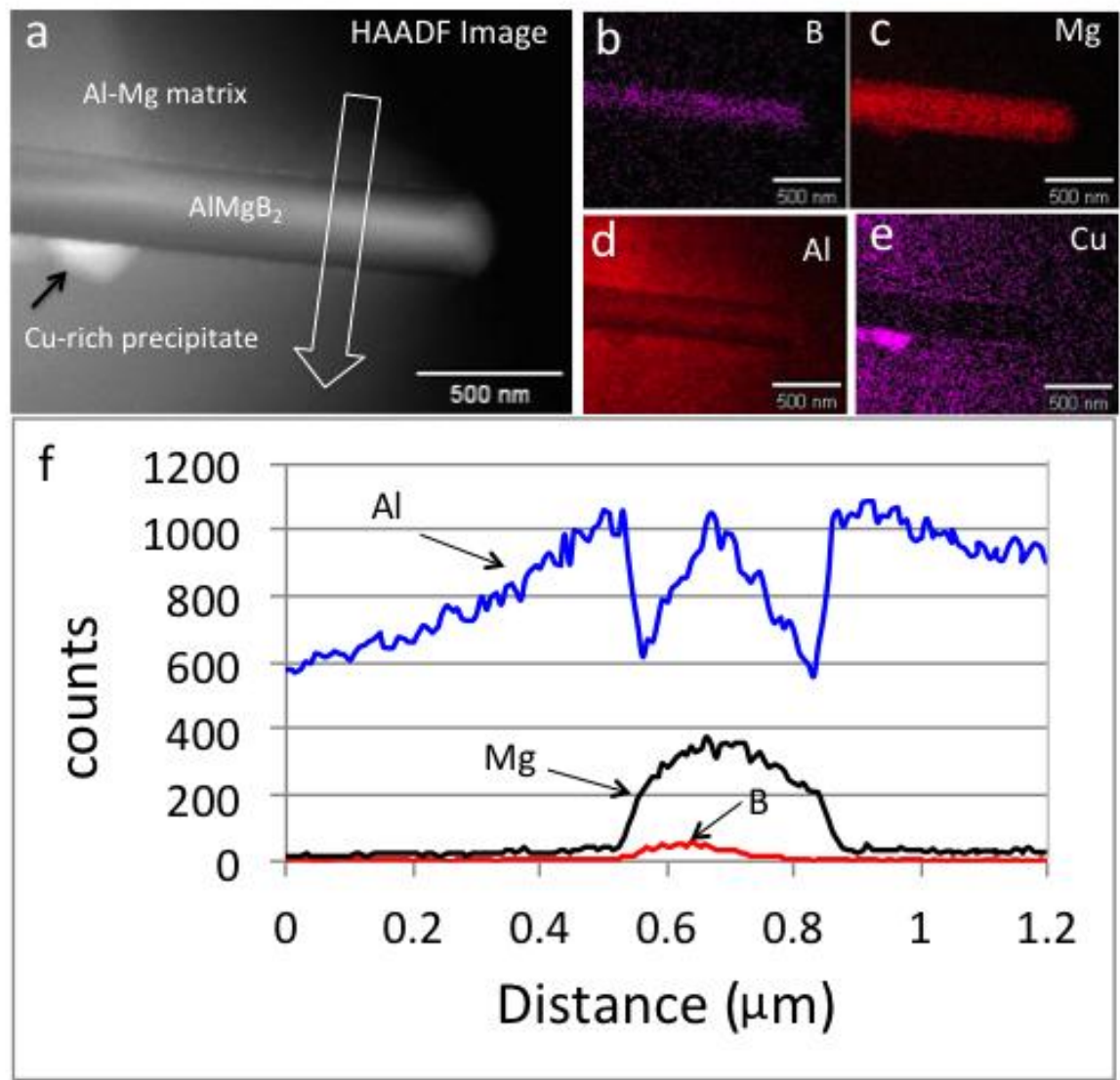

Fig. 1 


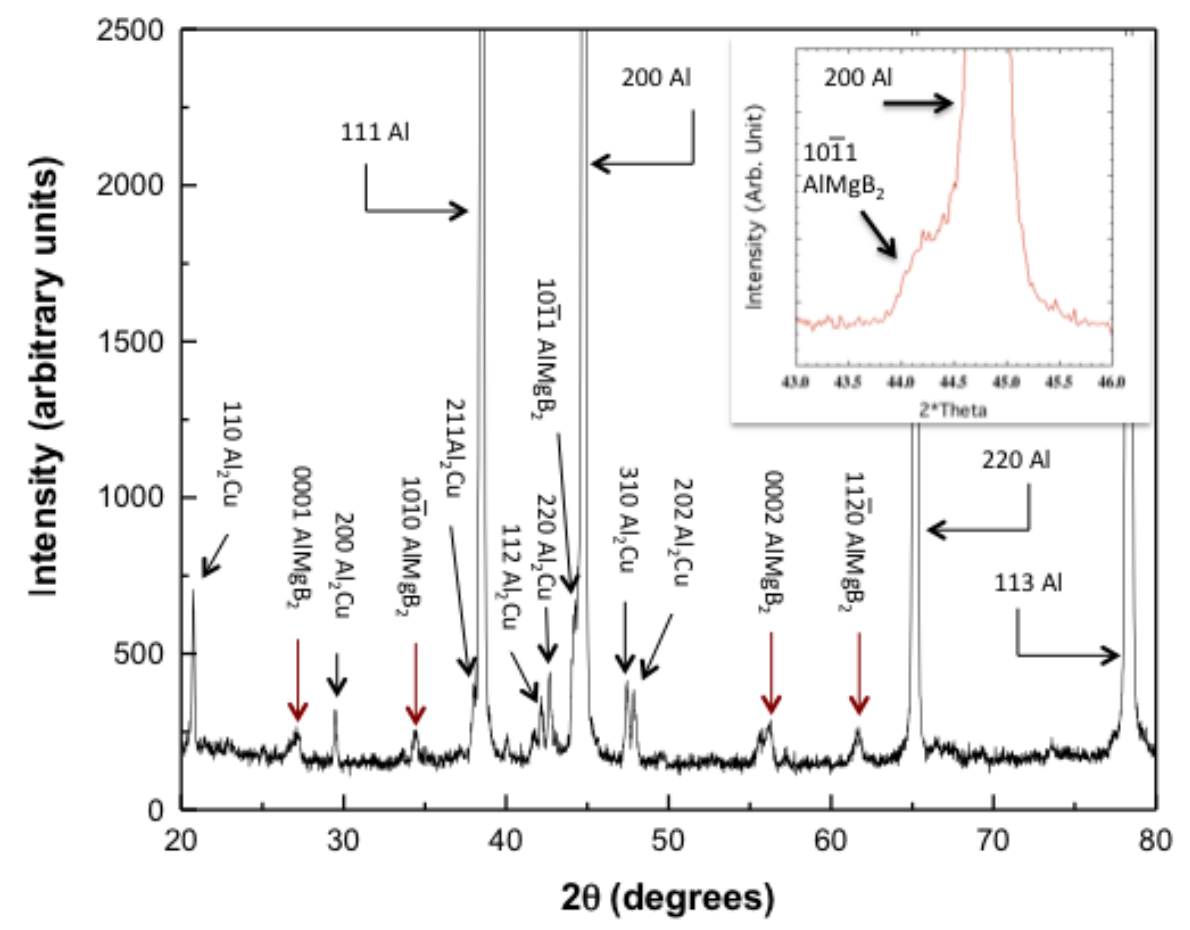

Fig. 2 


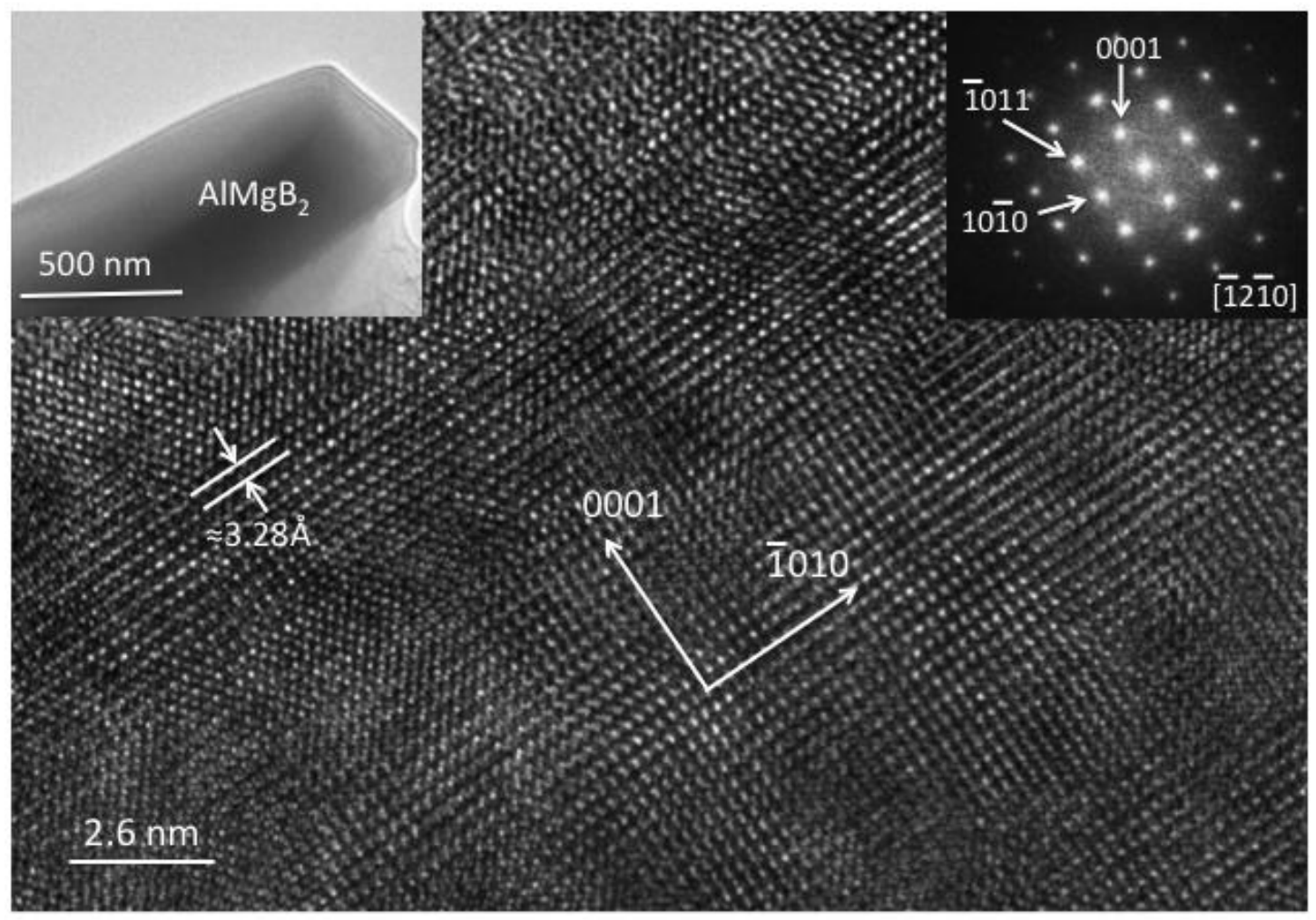

Fig. 3 

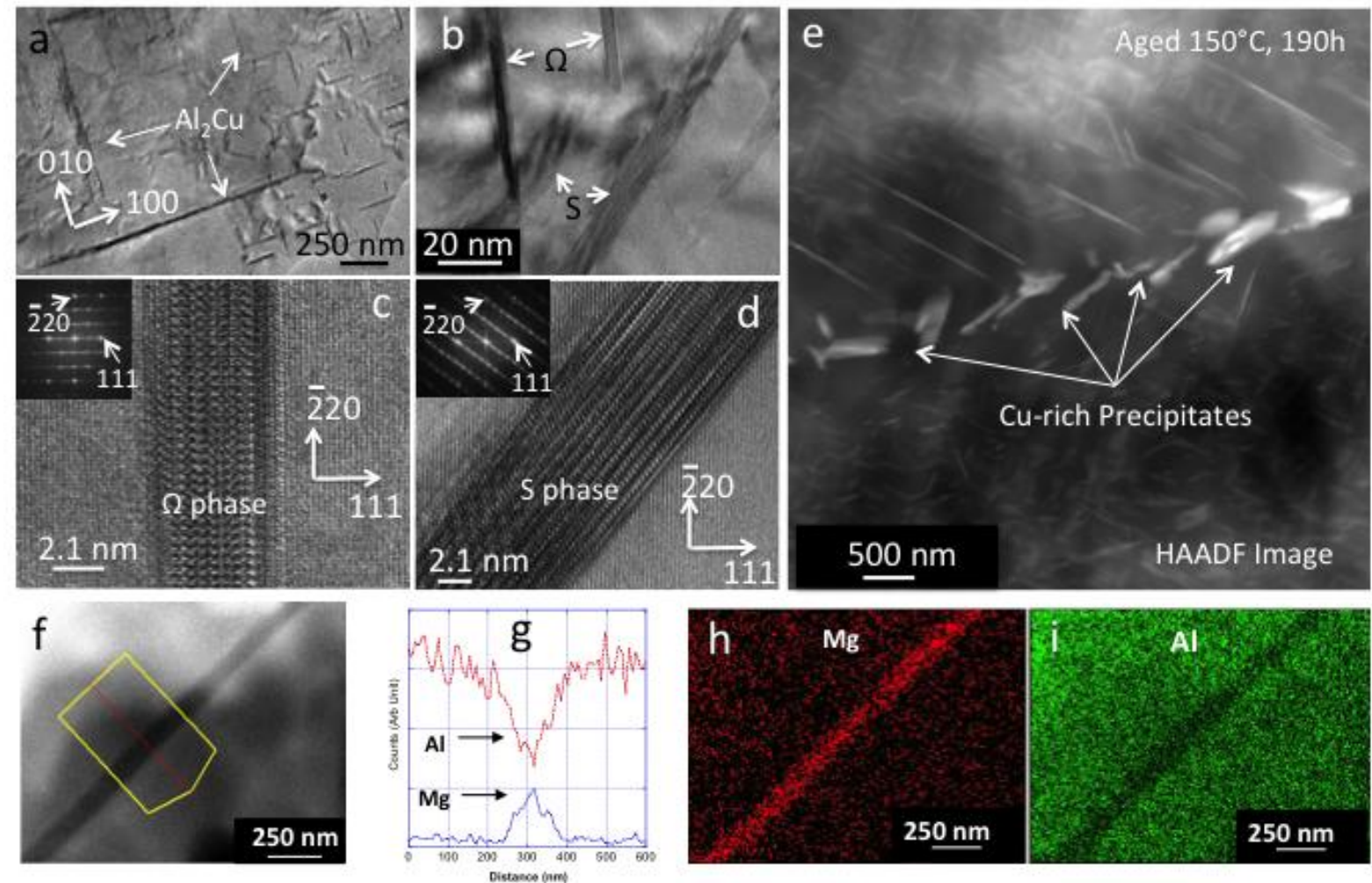

Fig. 4 